\title{
Screening Literacy in Education: Enhancing Cultural Understanding Through Film
}

\author{
Sukarni Suryaningsih* \\ English Department \\ Diponegoro University \\ Semarang, Indonesia \\ sukarnisuryaningsih@gmail.com
}

\begin{abstract}
As a tool to enhance the understanding about society and culture, using films in classroom activity is interesting and challenging. Visual elements become the advantegous point as learners can easily understand what is being reflected on the screen. Teaching topics about culture somehow has drawbacks since film also depicts stereotypes. Realizing that showing cultural aspects through film may also preserve stereotyping, this article examines the model of screening literacy so that the inclination led to stereotyping can be lessened. It means that students should understand and analyze the content, have discussion and design a better version of cultural representation.
\end{abstract}

Keywords -- film, screening literacy, stereotype, cultural understanding

\section{INTRODUCTION}

Film is a meaningful moving art that is a means to convey messages and express ideas. Compared to written literary texts, the visual and audio effects of films strengthen the meaning and reach the audience effectively. Sergei Einstein said that through images film provokes ideas and stimulate sentiment (Deer, 1967). This statement is certainly not excessive, especially when considering the era of globalization where the advances of information technology cause the exchange of knowledge through film to take place quickly and massively. The film and the messages that it brings connect the inhabitants of the global village not physically, but rather far more meaningfully it connects mentally. What appears through the communication media is easily accessed by wider community and provides knowledge of various things that are not only related to what is happening in other parts of the world, but also to how the culture and ways of life are adopted.

As a means of expressing messages and ideas, film is also an interpretive text that is persuasive and open. A single idea that might be put forward by a filmmaker can develop in many different meanings to the audience. Therefore, the process of giving meaning to films places the audience in an important position because, as the producers of meaning, audience are actively involved. Watching film as a text has various meanings and dimensions. It is not just an act that produces a passive relation of objects and subjects, but a dynamic and influential relationship.

One reminder about watching activity has important meaning is Wagner's opinion (Wagner, 1981) which says that watching film has a social dimension that is not only related to the media representation of society, or how the media has the ability to propagate something, but also provides an opportunity to train the audience's skills in cultural production. Watching therefore has the meaning of generative symbolic practices i.e. a social event carried out by the audience to produce certain cultural understandings. An anthropologist Michael Taussig calls it implicit social knowledge, that is, the ability to socially interpret things that are unarticulated, imaginary and nondiscursive (Taussig, 1987).

The strength of film is also considered as a source and means of learning in education, one of which is multiculturalism education. Multicultural education is a form of education in which the teaching learning process includes the elements of history, values, views from different cultural backgrounds. Film as defined by Roell (2010) is not only a source of learning related to language, but also a source of cultural learning. This is in line with Perry's opinion (2016) that a film with some appropriate adaptations and guidance is a strong authentic material to get cultural understandings.

Proper guidance during watching films is the so called screening literacy. Literacy screening does not always refer to the number of films watched that guarantees the exposure to films, but also the process of understanding the contents of the films so that the viewer can respond more wisely to the message conveyed. Screening literacy can also be applied when viewers notice the aspects of culture in a film, where the films often display stereotypical views or stigmatize a particular culture. Stereotype according to Lippman (1946) is a certain perpespective in our minds that represents the relationship between facts and reality and our subjectivity. Conventionally, a stereotypical view allows certain groups attribute something to other groups (2013). In presenting the material of multicultural education, discussing stereotypes and stigma becomes an inseparable part. However, if the final goal to be achieved from providing cultural experience through film is the emergence of a positive understanding among cultures, the teacher needs to make some efforts so that ethnic stereotyping can be minimized or the teacher can turn it into a positive stereotype. This study therefore aims to describe one of the alternatives to cultural topic teaching in which the materials might contain ethnic stereotypes.

\section{METHOD}

This study is a qualitative descriptive study that aims to explain the teaching implementation carried out in a class of 
multiculturalism, where the subjects of the study are the students of American Studies in English Department of Diponegoro University. The Multiculturalism class learns about the diversity of cultures in society, especially in the United States through various sources, especially literary works and films. Students see and discuss two films about two different societies, and the activity was followed with a close look at the relationships seen between the people of different cultures that appear in film Suzie Gold and Saving Face. Suzie Gold tells about the lives of Jewish ethnic, while Saving Face talks about people of Chinese descent. Data obtained are taken through classroom assessment methods which is direct observation of student learning activities.

\section{RESULT AND DISCUSSION}

This section discusses the steps taken by students to put films as a cultural experience (Champoux, 1999) in which watching films is used to understand different cultural aspects of the audience. In this series of discussion processes the teacher directs and guides the student discussion. The teacher becomes a facilitator of each stage. In the first stage, the teacher creates a conducive atmosphere to watch films that are selected based on the following criteria: 1 ). thematic culture of a community, 2). having a social setting in modern society, and $3)$. having characters that have various cultural differences.

In addition to the cultural aspects, other stereotyping issues that arise from the film Suzie Gold and Saving Face are also explored. The steps are:

\subsection{Watch the whole storyline of the film to get the integrity of the cultural experience.}

The first and foremost screening literacy process is watching the film intactly without having interuptions to get a good initial understanding, so that it helps students to have a discussion in the next stage. Watching the film in this first session, students did not get any instructions. This is done to prevent the students analyzing the film too early. The film watching session lasts for 1.5 hours where students are not allowed to do other activities, such as taking notes or recording. When watching film, the teacher controls the concentration and seriousness of the students by creating an atmosphere that does not allow them to do any other activity besides watching. Teachers give warnings or take decisive actions if there are students who interfere with the process of watching film.

From the film Suzie Gold students see the life of a young woman of Jewish descent who lives in a modern society with a deep cultural attachment. Life for Suzie has a very clear pattern, i.e. get married to a man of Jewish descent and preserve Jewish descent. As a woman who is not too restricted in terms of career, Suzie loves her job at a television station and considers career as one of the things that makes her life interesting. Later, in her workplace she meets Darren, a nonJewish man who makes her fall in love.

On the other hand, a Jewish woman's life has always been echoed by the character of Suzie's mother that a Jewish woman is expected to marry a Jewish man and maintain Jewish traditions. Knowing that she is in love with someone with different cultural background, Suzie covers up her love affair with Darren. Her parents really wanted her to marry Anthony, a Jewish man who was considered to have a successful life. Suzie's actions and her parents' views in seeing the demands of Jewish culture cause various problems and conflicts which provoke the audience, in this case the students, to pay close attention to and ponder on them.

Likewise, the story of the film Saving Face is about the struggle of Will, a Chinese woman who hides her same-sex relationships from her extended family. Gao, her mother who sees that Will's life has been dominated by work as a doctor, wants her daughter to have a happy love life and to have normal marriage with a lot of kids like her cousins in their extended family. What Gao does not realize is that Will has a romantic relationship with a lesbian professional violinist who is the daughter of her boss. She does not want to tell her mother about this relationship because she was afraid that she would be ashamed of the same-sex relationship she is having.

While on the other hand, at the same time, Gao is also hiding her love affair from her daughter. She also feels ashamed if her daughter will look down on her because of her relationship with a traditional Chinese herbalist trader in the neighborhood. Both mother and daughter experience various events that test not only their relationship as mother and daughter, but also their relationship with their ethnic community which is still strong in preserving Chinese traditions and customs.

3.2. Discuss cultural aspects that emerge from the story which include kinship relations, professional life and the relations of majorities-minorities.

At this stage, students are divided into groups to discuss the themes that the teacher has addressed. This guided discussion model is needed so that the discussion will focus more on the dimensions that are the main topic of study. The teacher devides the class into 3 groups, namely kinship group (A), social and professional group (B) and majority-minority group (C). The group that discusses kinship relations focuses on the relationship between the nuclear family and extended family depicted in both films. This includes looking at parenting aspect which ends up exploring seniority determination in a particular culture. In a communal cultural perspective, the existence of seniority or those who are older, have a great influence on family and society. Opinions and decisions from the elder influence their surroundings, so that by understanding this kinship relationship students will understand how the changes that take place from the social settings of these two films affect the whole story.

Through the film Suzie Gold and Saving Face, group A explained that the nuclear family in both Italian and Chinese cultural backgrounds fully embraced communalism. This can be seen from several scenes that illustrate the existence of routine and incidental meetings that are often held by the community to familiarize themselves and exchange news. The kinship style that is inclusive of ethnic groups, according to 
students, has the meaning to make their generation attach to the values of Italian and Chinese culture; those values are very important for the continuity of their existence in a modern and increasingly plural society. The kinship community activities, in both Suzie Gold and Saving Face, become informal venues for the seniors to tell the young (Suzie and Will's generation) about their cultural identity while reminding them about cultural values. Usually giving advice will come after an uncomfortable incident or when a member of the community opens a conversation with the aim of exchanging gossip about the community members, especially influential and respected figures.

The close relationship of parents to children is also a topic discussed by the students in this group, especially on how both the parents of Suzie and Will educate and guide their daughters. Regarding parenting, Group A explained their opinions referring to the pattern of parenting according to Baumrind (1991) who defines it as all forms and processes of interaction that occurs between parents and children in the form of certain care in the family which will influence the development of the child's personality. Baumrind divides parenting patterns into three styles. First, democratic parenting is to place priority on the interests of children. Second is authoritarian parenting that tends to set absolute standards that must be obeyed, and they usually are followed by threats. Parents of this type also do not want the compromise while the communication is usually one-way. Third, neglectful parenting or known as permissive parenting. A style where parents are very much not involved in the child's life.

From this point of view, the students' discussion in this group concluded that the parenting that was carried out by both Suzie and Will's parents was a democratic parenting, where from such a parenting model they found that children and parents, although faced with cultural clashes, finally are able to accept differences of opinion with their children. Democracy is interpreted by the students as compromising values that combine different views to gain understanding.

The results of democratic parenting, according to students, can be seen from the professional achievements made by the female figures Suzie and Will. As women born in strong communal cultural traditions, the two characters in this film managed to become successful career women. This professional achievement means that the parents of these two female characters give freedom to actualize themselves outside their home, a view that is different from most of the views of the Jewish community and the community of Chinese descent who expect women to be more active in domestic and family matters.

Another interesting thing that emerged during the group discussion was that group $\mathrm{C}$ looked at the relationship between Suzie as a Jewish minority to Darren, who represented the majority of non-Jewish white Europeans. It is also the relationship that exists between Will as a Chinese minority with a minority of African descent, Jay, who was a good friend of Will. By looking at the comparison of these two relations, students see that between Suzie and Darren and the situation surrounding them, the perspectives related to cultural differences are not too prominent. This group concluded it because Darren figure physically is not presented in the middle of Suzie's family or in other words his existence is hidden by the Suzie character. On the other hand, the relations among minorities that appear in Will and Jay's relationship are more prominent because their friendship has no other interests. In this association, Ma character or Will's mother expressively shows the stigma of her view about Jay's nature and habits that make her feel uncomfortable.

The results of the discussion in the second stage aim to open students' insights into the cultural aspects contained in both Suzie Gold and Saving Face films. Knowledge of these aspects strengthens the cultural experience even though they are not physically present in the middle of the Jewish ethnic community or the Chinese community. Discussions conducted after the film screening have a positive impact because the students can compare between the topic of discussion with the visual image they have witnessed (Champoux, 1999). In addition, by watching the film first, it is expected that the audience is in a more neutral situation since they do not build pre assumptions, but instead enjoy the film as a film. In other words, it minimizes stereotypes or negative stigma perspectives.

\subsection{Repeat watching the same film to notice interesting parts related to perceptions among ethnicities and races.}

At this stage, before the film was shown for the second time randomly, the teacher gives opportunity to the students to share the previous knowledge about the characteristics of the Jewish ethnicity and the Chinese characteristics that they gained from various sources both in the form of reading and watching. The knowledge they shared in front of the class related to the topic of discussion can be described in the following table.

\begin{tabular}{|c|l|l|}
\hline & Jewish & Chinese \\
\hline Kinship (A) & $\begin{array}{l}\text { strong family bond, } \\
\text { help among Jewish, } \\
\text { cold quiet serious } \\
\text { characteristic }\end{array}$ & $\begin{array}{l}\text { strong family bond, help } \\
\text { among Chinese, have a } \\
\text { strong cultural identity }\end{array}$ \\
\hline $\begin{array}{c}\text { Social and } \\
\text { Professional (B) }\end{array}$ & $\begin{array}{l}\text { intelectual, } \\
\text { brilliant, thinker, } \\
\text { knowledgeable, } \\
\text { ruler of the world, } \\
\text { mysterious, full of } \\
\text { strategy, the best in } \\
\text { his field }\end{array}$ & $\begin{array}{l}\text { Mastering the trading } \\
\text { business, the model } \\
\text { minority, getting } \\
\text { success because of } \\
\text { great endurance }\end{array}$ \\
\hline $\begin{array}{l}\text { Majaority-Minority } \\
\text { (C) }\end{array}$ & $\begin{array}{l}\text { Nazi victims, } \\
\text { holocaust, } \\
\text { experience } \\
\text { prejudices }\end{array}$ & $\begin{array}{l}\text { Getting better } \\
\text { treatment than other } \\
\text { ethnics/races, } \\
\text { experience } \\
\text { discrimination and } \\
\text { prejudices, finding } \\
\text { safety }\end{array}$ \\
\hline
\end{tabular}

From the collected phrases, most of the students have 
already had the picture in their mind about those two ethnics. Several students expressed that they already had certain mindset, which they had neither discovered nor found in the film Suzie Gold and Saving Face. In terms of kinship relations, in Suzie Gold, it turns out that it is not Jewish families who are quiet and closed like what they had in mind. Suzie Gold's family is an expressive happy family. Yet the students had to interpret this because the story line includes only similar Jewish ethnic; the film does not show scenes when they interact with other ethnic groups. It means that ethnic internal relations are warm and open, but will this apply when they interact with other ethnic groups? While in Chinese setting, students agreed that they hold tightly the cultural tradition wherever they live. In Saving Face, there are several scenes that show when the characters in this film perform traditions such as putting parents first when eating and gathering, performing ethnic ritual traditions such as ceremonies on certain days that are considered sacred, performing traditional gymnastics like tai chi with other Chinese descendants. This means that the students' knowledge about China as a strong tradition beholder is strengthened after watching the film.

Next, it is about the social and professional world in Suzie Gold in which students watched the life of Jewish in general, whose level of economic achievement is in the middle class with professional achievements that are also not as prominent as they usually imagine about Jewish society. While on the other hand, Will's profession as a doctor and her partner who is a violinist, negates their perceptions of Chinese who are professionally often involved in economics and trade. The condition of Will's family confirms the knowledge of the students that Chinese are poverty-stricken to achieve success. This is proven by the strength of Gao character who managed to educate Will to become a surgeon.

From the discussion that took place in stage 3 , it was found that the students as film viewers had the knowledge of Jewish and Chinese cultural background that had become a kind of stigma. The process of watching those films confirms what they understand and find some new findings about those ethnic cultures. The expected neutrality of viewing the cultural setting of the story is not successfully achieved because of the previous knowledge of the students. This means that the process of making meaning construction happens continously- before, when it happens and afterwards.

\subsection{Discuss alternative stereotype-free dialogue scenes}

In this session, teacher starts to guide the students to discuss the previous findings and to think about some alternatives based on their findings. As an example, students in group $\mathrm{C}$ discussed their findings from the scenes in the two films that are related to negative views about other ethnic/races. This discussion aims to design dialogue scenes with negative stereotypes to be more positive. Most students choose Saving Face as the film which contains negative stigma-filled dialogue. This can be seen from the presence of
Jay character, who are African American, as Will's good friend who interacts with Gao character on a dinner occasion. Jay's style is considered to be impolite by Gao, so this provokes her to give a negative label which is then associated with Jay's skin color.

\begin{tabular}{|c|c|}
\hline Gao & : His shoes! His shoes! \\
\hline Jay & : Hi, Mrs. Pang \\
\hline Will & : You remember my neighbor, Jay. \\
\hline Gao & : His shoes! You don't have to talk so loud. \\
\hline \multicolumn{2}{|c|}{ And leave your shoes by the door. } \\
\hline Jay & : So I get a call from .... \\
\hline $\begin{array}{l}\text { Gao } \\
\text { much }\end{array}$ & $\begin{array}{l}\text { : Your neighbor is loud and dark and eats too } \\
\text { auce. }\end{array}$ \\
\hline Will & : Americans like soy sauce. \\
\hline $\begin{array}{l}\text { Gao } \\
\text { it wor }\end{array}$ & $\begin{array}{l}\text { : I'm going to start eating less soy sauce ... so } \\
n \text { the baby too dark }\end{array}$ \\
\hline Will & : Ma, that's ridiculous \\
\hline Gao & : You eat less too, so you don't grow spots. \\
\hline
\end{tabular}

Then group $\mathrm{C}$ discussed the elements that build the emergence of the dialogue. Some of the things they discussed were Gao's very open expressiveness, whereas Eastern culture is taught to restrain expression when dealing directly with strangers who were first encountered. This aroused the students' curiosity why Gao chose such an open attitude that could potentially make racial harassment, why Gao dared to insult the color of his guests, why Jay seemed unaffected by the insult, and why Gao did not respond to Will's warning for behaving friendly.

\subsection{Perform the dialogue scene in front of the class}

The final stage of screening literacy which aims to minimize negative stereotypes is to present the results of group discussions by performing one of new versions of dialogue scenes written by the students. In this stage, the teacher can stimulate the students to respond to the group performance in terms of the choice of expression. The performed dialogue has been redesigned so that the characters do not use expressions that are stigmatized on certain ethnic/racial groups. Below is the example of the redesigned dialogue scene:

$\begin{array}{ll}\text { Gao } & : \text { (smiling instead of disliking) } \\ \text { Jay } & \text { : Hi, Mrs. Pang } \\ \text { Will } & \text { : You remember my neighbour, Jay. } \\ \text { Gao } & \text { : Hello Jay. You can put your shoes by the } \\ \text { door } & \\ \text { Jay } & \text { : Oh okay Mrs.Pang } \\ \text { Gao } & \text { : Seemingly Jay likes soy sauce } \\ \text { Will } & \text { : Sure he does } \\ \text { Gao } & : \text { I'm going to start eating soy sauce ... so the } \\ \text { baby will be healthy } \\ \text { Will } \quad: \text { That's good } \\ \text { Gao } \quad \text { : You eat more if you want, it makes you full } \\ \text { of spirit like Jay }\end{array}$


Since film has a strong message because of the visual aspects, practicing the dialogue scene is also expected to reinforce a strong message for the students because of the presence of theatrical elements that occur when characterizing the dialogue in front of the class.

\section{CONCLUSIONS}

Screening literacy is one of the ways to study cultural material through films or other visual aids that contain stigma and stereotypes of certain ethnicities. Through this method, teacher can help students understand various cultural differences and understand alternatives that can be done to get cross-cultural understanding. The most fundamental thing that distinguishes screening literacy from watching techniques in general is the presence of discussions aimed at redesigning conversations or scenes with negative stereotypes, directing students to construct scenes or dialogs that are stereotype-free and practicing the dialogue to reinforce positive stereotype and get better cultural understanding. A good and adequate crosscultural understanding is very important in helping students develop their character so that they are more tolerant and respectful of differences, and at the same time wiser in dealing with the increasingly diverse society in this global era.

\section{ACKNOWLEDGMENT}

Some parts of this paper are a prelimenary study of research dissertation supervised by Prof.Dr.Juliasih K, S.U and Budi Irawanto, M.A, $\mathrm{PhD}$.

\section{REFERENCES}

Baumrind, D. (1991). Effective Parenting during the Early Adolescent Transition. In P.A. Cowan \& E.M. Hetherington (Eds), Advances in Family Research (vol 2), New Jersey: Erlbaum.

Champoux, Joseph E. (1999). Film as Teaching Resources. Journal of Management Inquiry 8(2): 240-251.

Czopp, Alexander M; Kay, Aaron C; Cheryan, Sapna. (2015). Positive Stereotypes are Pervasive and Powerful. Perspectives on Psychological Science Vol 10 (4): 451-463.

Deer, Irving and Harriet A.Deer. (1967). The Popular Arts - A Critical Reader. USA: Charles \& Screibners\&Son.

Lee, Y; Jussim L; McCauley CR. (2013). Stereotypes as Categories of Knowledge: Complexity, Validity and Usefulness, and Essence in Perception of Group Difference. Advances in Psychological Science. 2013; 21 (1) 1-21. http://dx.doi.org/10.3724/SP.J.1042.2013.00001

Lippmann, Walter. (1946). Public Opinion. New Jersey : Transaction.

Perry, Patricia Comello. (2016). Fostering Culture through Film : Fostering Intercultural Teaching through Film. UK: Cambridge Scholars Publishing.

Roell, C.(2010). Intercultural Training with Films. English Teaching Forum $48(2): 2-15$.

Saenz, Michael, (1992). Television Viewing as a Cultural Practice. Journal of Communication Inquiry, 16:2:37-51.

Santrock, J.W. (2010). Life-span Development 13th ed. New York: McGrawHill.

Taussig, Michael. (1987). Shamanism, Colonialism and The Wild Man : A Study in Terror and Healing. Chicago : University of Chicago Press. Wagner, Roy. (1981). The Invention of Culture Rev,ed. Chicago : University of Chicago Press.. 